\title{
Letters
}

\section{Policies on SARS in UK boarding schools are confused}

EDIToR-The former Public Health Laboratory Service (PHLS) (now Health Protection Agency) states that there is no need for students returning from areas affected by the severe acute respiratory syndrome (SARS) to be excluded or quarantined unless they are unwell. ${ }^{1}$ However, the agency is aware that some schools are advising parents differently. ${ }^{1}$ Unfortunately, some Chinese students are subjected to quarantine imposed by their schools, which becomes very disruptive to these students' schooling. One boarding school was reported to be excluding students returning from certain parts of the Far East after Easter. ${ }^{2}$

After receiving inquires from anxious Chinese guardians about whether Chinese students should be quarantined, I searched the internet using the terms "SARS" and "school" on www.freeserve.com to identify policies about the syndrome in different schools. After visiting the first 100 websites in the United Kingdom, I identified the policies of 10 schools. The table shows the results.

Summary of school policies on severe acute respiratory syndrome identified through internet search

\begin{tabular}{|c|c|}
\hline Policy & No of schools \\
\hline $\begin{array}{l}\text { Public Health Laboratory Service's } \\
\text { recommendation }\end{array}$ & 5 \\
\hline \multicolumn{2}{|l|}{ School's own policy: } \\
\hline Up to 10 days' quarantine is required & 4 \\
\hline $\begin{array}{l}\text { Advise students not to return to the } \\
\text { school for the summer term until such a } \\
\text { time that the school is satisfied that the } \\
\text { virus is understood, contained, and an } \\
\text { appropriate treatment is available }\end{array}$ & 1 \\
\hline
\end{tabular}

One school representative raised an important discrepancy: "a lack of congruence across UK boarding schools, many of which are adopting different strategies, to both include and exclude Chinese students from returning to school for the summer term."' Furthermore, one concerned parent told a newspaper: "They [local students] are only back for a couple of weeks before exam leave starts, so I hope the school will be keeping students returning from affected countries separate for the incubation period to be on the safe side." ${ }^{*}$ The situation looks confusing.

I urge the Department of Education and Skills and the Department of Health to work together in this matter urgently and develop a common policy for schools. This will assist schools in making rational decisions and more importantly address the fears of parents and children.

Ian Wong director

Centre for Paediatric Pharmacy Research, School of Pharmacy, University of London and the Institute of Child Health, University College London, London WC1N 1AX ian.wong@ulsop.ac.uk

IW's post is funded by a public health career scientist award from the Department of Health. Competing interests: None declared.

1 Severe acute respiratory syndrome (SARS). Advice for boarding schools and other institutions with large SARS areas. Revised 11 April 2003. www afphlscouk SARS areas. Revised 11 April 2003. www.phls.co.uk/ 2003)

2 Capper M. SARS death toll hits 13 in Canada. Metro 2003 Apr 14:12.

Press release 7 April 2003. Rossall postpones start of summer term for Chinese students. wwwrossallschool ros/indexphp (accessed 13 Apr 2003). Adison M. Pupils face killer bug quaprine wo Addison M. Pupils face killer bug quarantine. Www (accessed 16 Apr 2003).

\section{EU working time directive}

\section{More doctors is truly not the answer}

EDITOR-In its statement that the European working time directive should be implemented for doctors in training without simultaneously increasing numbers of doctors, ${ }^{1}$ the Department of Health is revealing a tacit acceptance of lower standards of care for patients. Its recommended alternatives to increasing medical staffing serve only to make the reduction in hours affordable.

Over the past 10 years, since the first initiative to reduce junior doctors' hours of duty, medical cover on wards has been progressively reduced and the standards of care provided have consequently declined, particularly postoperatively. Consequently problems are detected late, sometimes when corrective action is no longer possible.

The merit of reducing further the hours of work is for debate elsewhere, but if it is believed to be necessary it is folly to suggest that it can be done without replacing the doctors taken from the wards with others of equal standing. A football team playing with only 10 men is not the same effective unit as the full side. It may make do, by extra effort, for a short while, but it will not be able to sustain performance throughout the season.
The statement of the chairperson of the junior doctors' negotiating committee, that hospital mergers may be inevitable to produce the critical mass of doctors required to ensure patient safety, suggests humble expectations. We should surely be offering more to hospital patients than basic safety.

Alan R Berry consultant surgeon

Northampton General Hospital, Northampton NN1 5BD alan@aberry.fsnet.co.uk

Competing interests: None declared.

1 Macdonald R. More doctors in not the answer to the EU working time directive. BMJ 2003;326:68. (11 January.)

Directive will be biggest driver for change in delivery of medical care

EDITOR-The working time directive will herald a major change in the delivery of medical care in hospitals. ${ }^{1}$ Avoiding recruitment of extra doctors, and consultants in particular, in the early phases of implementation will make any plan unmanageable.

Shift work will be a solution only in some areas with a requirement for staff in a specialty to be on site for 24 hours. To staff a rota over 24 hours, seven days a week, that incorporates prospective cover for annual leave, continuing professional development, commitments to continuing medical education, and a contingency for unplanned events such as illness will require a minimum of nine or 10 doctors for one to be available, with a built in handover period for patients undergoing treatment.

Senior doctors in many countries are already covered by the working time directive and will therefore not be in a position directly to increase their hours to compensate for reduced working hours for junior doctors. If work is to be redirected to other new grades of technical staff they will have to be trained. Reducing working hours for junior doctors should not result in an expansion of this grade as this will not enhance quality of care for patients, who will be even less likely than now to be treated by a consultant in the early stages of their illness. It will also affect the career progression of this group.

\section{bimj.com}

Letters appearing here are an edited selection of rapid responses originally posted on bmi.com

We ask for all letters to the editor to be submitted as rapid responses via bmj.com

For advice see: bmi.com/rapidresponses 
In the Republic of Ireland initiatives have been taken by the training bodies which will remove training accreditation from emergency departments that do not have an eight session consultant commitment in emergency medicine.

The directive is inevitable; we should do what we can to encourage early implementation locally, improving junior doctors' working and training conditions and making the hard decisions for those politicians unwilling to do so.

Michael S Molloy clinical fellow, emergency medicine St Vincent's University Hospital, Dublin, Republic of Ireland

drmick@eircom.net

Competing interests: MSM is a past president of the Irish Medical Organisation.

1 Macdonald R. More doctors is not the answer to the EU working time directive. BMJ 2003;326:68. (11 January.)

\section{Effectiveness of hip protectors}

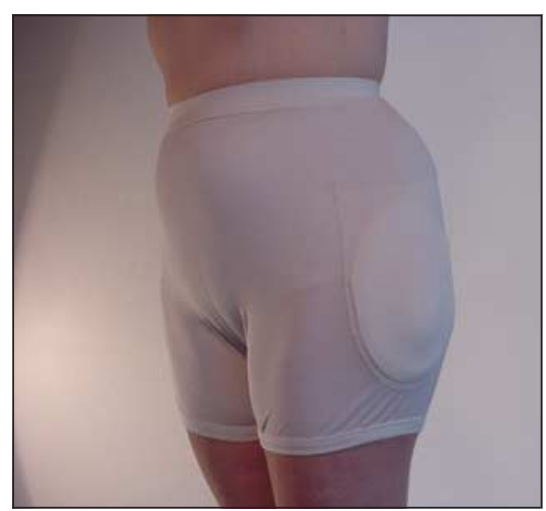

Results may not be generalisable to the community

EDITOR-The hip protector trial reported by Meyer et al is methodologically a notable improvement on previous hip protector trials. ${ }^{1}$ However, some methodological shortcomings affect the study, and issues arise about its generalisability to people at high risk who are not resident in nursing homes.

An important problem, not noted by the authors, is that the study groups have differential loss to follow up. In the intervention group $64 \%$ of the participants completed the 18 month follow up compared with only $57 \%$ of the controls $(\mathrm{P}=0.04)$. This difference can introduce selection bias and could give a false estimate of effectiveness. In addition, there seems to be some evidence that the control group may have been frailer than the intervention group as the death rate was somewhat greater and this may have explained the higher incidence of falls in the control group. These differences could explain some of the apparent effectiveness of the hip protectors.

Interestingly, the compliance rate for the hip protectors was very low, at only $35 \%$, not $68 \%$ as implied in the abstract. This low compliance rate is similar to that in our ongoing community study in which we simply post hip protectors to participants at high risk.
Finally, although these data may support the use of hip protectors among nursing home residents, evidence for their effectiveness among older people at high risk who are living in the community is still required. We are undertaking a large individually randomised trial among 4200 women at increased risk of hip fracture living in the community, the results of which will be reported this summer.

David Torgerson director, York trials unit Jill Porthouse trial coordinator, primary care hip protector study

University of York, York YO10 5DD

Competing interests: None declared.

1 Meyer G, Warnke A, Bender A, Muhlhauser I. Effect on hip fractures of increased use of hip protectors in nursing homes: cluster randomised trial. BMJ 2003;326:76. (11 January.)

\section{Effectiveness of studied hip protector was uncertain}

EDITOR-The trial reported by Meyer et al left the main issue of effectiveness of the studied hip protector unanswered.

Firstly, many important baseline characteristics or risk factors of hip fracture were not reported and included in the analysis. The hip protector group and the control group were not directly comparable since more controls could not be followed up to the end of the trial and had a (29\%) higher incidence of falling than people in the protector group (both variables referring to more frailty in the controls).

Secondly, since the difference in the risk of hip fracture in the two groups was non-significant the preventive effect of the hip protector remained uncertain. This is also seen as an open end in the $95 \%$ confidence interval of the calculation of the number needed to treat. The authors' speculation about using a one sided hypothesis is not on firm ground: statisticians would not accept one sided hypothesis because at least two previous trials of the studied protector model have shown no effect. ${ }^{23}$

Thirdly, although a possible cluster effect was taken into account, analysis without cluster randomisation was not provided. It therefore remained unknown whether adjustment for this procedure had any effect on the relative risk of fracture and its $P$ value. For falls, it had little effect.

Fourthly, since Meyer et al could not provide the fracture data for protected and unprotected falls in the two groups, the biomechanical efficacy of the studied protector in actual falls remained unclear. This information would also have been essential in interpreting the given relative risk of hip fracture, since the claimed risk reduction of $40 \%$ on an intention to treat basis in the protector group can be true only if the risk of falls was clearly reduced: about half of the falls in the protector group occurred without the protector.

Pekka A Kannus chief physician

Accident and Trauma Research Center, FIN-33500 Tampere, Finland

kipeka@uta.fi

Competing interests: None declared.
1 Meyer G, Warnke A, Bender R, Mühlhauser I. Effect on hip fractures of increased use of hip protectors in nursing fractures of inctease use hip protectors in nursing 003.326:76-8. (11 Janum

Cam,326.76-8. (11 Jan J .) Cameron ID, Venman J, Kurrle SE, Lockwood K, Birks C, Cumming RG, Quine S, Bashford G. Hip protectors in hed-care facilities: a randomized trial of use by ind

3 . 3 Hildreth R, Campbell P, Torgerson D, Watt I. A randomised ond hip fractures. Osteoporos Int 2001;12(suppl 2):S13.

\section{Some clarifications would be useful}

EDITOR-Meyer et al examined factors influencing the use of hip protectors in nursing homes. ${ }^{1}$ The analysis was adjusted for the effects of clustering, and the study provides stronger evidence for effectiveness of hip protectors than previously published studies. $^{2}$ We hope that the authors can provide further information to help others in applying the findings of the study.

What proportion of nursing home residents received (and understood) the educational intervention and what proportion were simply encouraged to wear hip protectors by the staff who had received the education are unclear. In Australia and other countries most residents of nursing homes have severe cognitive impairment, limiting their participation in decision making about the use of hip protectors. We would be interested to know what percentage of participants in this study had severe cognitive impairment.

The cost of hip protectors is clearly a disincentive to their use in countries such as Germany where they are not subsidised. Could Meyer et al speculate on how much of the effect of the intervention was due to the supply of free hip protectors and how much to the educational session? Were three pairs of hip protectors enough for the 15 months of the study? In our experience more than three pairs would be required if they are used regularly.

Reasons for non-adherence to using hip protectors should be elaborated as measures to address these might improve the limited adherence rates reported in this study. Some other methodological issues could be clarified, such as how hip fractures were ascertained.

Clarification of these issues would help clinicians working with older people at high risk of hip fractures. Several review articles recommend hip protectors for older people who have had multiple falls, ${ }^{3}$ and further evidence based information is necessary to ensure their appropriate use.

Susan E Kurrle senior staff specialist geriatrician Hornsby Ku-ring-gai Hospital, Hornsby, NSW 2077, Australia kurrle@bigpond.com

Ian D Cameron chair, rehabilitation medicine Rehabilitation Studies Unit, University of Sydney, PO Box 6, Ryde, NSW 1680, Australia

Competing interests: None declared.

1 Meyer G, Warnke A, Bender R, Mühlhauser I. Effect on hip fractures of increased use of hip protectors in nursing homes: cluster randomised controlled trial. BMJ 2003; 326:76-8. (11 January.)

2 Parker MJ, Gillespie LD, Gillespie WJ. Hip protectors for preventing hip fractures in the elderly. Cochrane Database Syst Rev 2002;4:CD001255.

3 Tinetti ME. Preventing falls in elderly persons. NEngl J Med 2003;348:42-9. 


\section{Authors' reply}

EDITOR-Torgerson and Porthouse and Kannus are wrong in assuming that the two groups were not comparable. Our optimal randomisation procedure ensured the comparability of groups as shown in similar baseline characteristics. There were no losses to follow up.

The trend to fewer falls and lower mortality associated with longer observation in the intervention group could be a result of the intervention. Analyses based on survival times taking into account different follow up times as well as cluster randomisation by using either $(a)$ a Cox model with frailty or $(b)$ a Cox model with robust score test to allow for correlation within clusters would yield the following estimated hazard ratios and two sided $\mathrm{P}$ values for the primary outcome of hip fracture: (a) hazard ratio $0.53, \mathrm{P}=0.028 ;(b)$ hazard ratio $0.52, \mathrm{P}=0.066$. These results are similar to the reported results of the cluster adjusted $\chi^{2}$ test (relative risk 0.57, $\mathrm{P}=0.072)$; analysis not taking cluster randomisation into account would yield a lower $\mathrm{P}$ value $(\mathrm{P}=0.034)$.

When we planned our study there was already strong evidence from a randomised controlled trial that Safehip protectors prevent hip fractures. ${ }^{1}$ Therefore, we chose a one sided hypothesis but we reported results for two sided 5\% tests according to $B M J$ policy. We used the Safehip protector because it was the only protector available when we initiated the study. The studies cited by Kannus are small trials lacking the power to detect differences between groups, ${ }^{23}$ and one is published in a supplement. ${ }^{3}$ In our study no hip fractures occurred with unambiguously documented use of the protector in either group.

Adherence was assessed by documenting hip protector use during a fall. We could not document how many of the residents who did not fall during the study were using the protector. Therefore, the proportions of residents who used the hip protector are worst scenario estimates based on the assumption that no resident without falls had used the hip protector. We included these figures on the request of the $B M J$ reviewers. Since these data are prone to misinterpretation we still think that they should not have been reported.

We have no separate data on the proportion of participants with severe cognitive impairment or on the proportion of residents who had participated in the programme in small groups. For further details on protected and unprotected falls, assessment of fractures (not blinded), and characteristics of the complex intervention programme we refer readers to the full paper on bmj.com. Space limitations prevent us discussing the reasons for non-adherence.

Gabriele Meyer research fellow

Andrea Warnke research fellow

Ingrid Mühlhauser professor

Ingrid_Muehlhauser@uni-hamburg.de

Unit of Health Sciences and Education, University of Hamburg, Martin-Luther-King-Platz 6, D-20146 Hamburg, Germany
Competing interests: AW was formerly an employee and is at present a consultant of Rölke Pharma, the German distributor of Safehip. AW and GM have received travel grants from Rölke Pharma.

1 Lauritzen JB, Petersen MM, Lund B. Effect of external hip protectors on hip fractures. Lancet 1993;341:11-3.

Cameron ID, Venman J, Kurrle SE, Lockwood K, Birks C Cumming RG, et al. Hip protectors in aged-care facilitie a randomized trial of use by individual higher-ris esidents. Age Ageing 2001;30:477-8

3 Hildreth R, Campbell P, Torgerson D, Watt I. A randomised controlled trial of hip protectors for the prevention of second hip fractures. Osteoporos Int 200 1;12(suppl 2):S13

\section{Quality of impact factors of general medical journals}
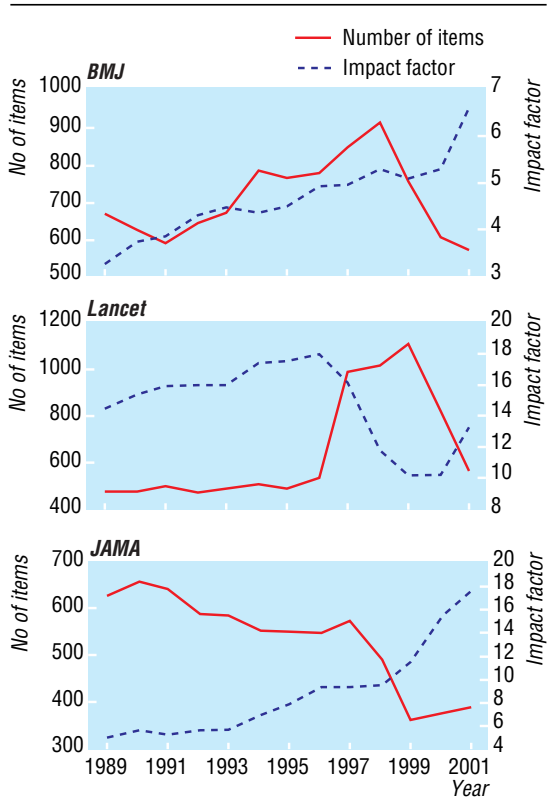

See p 283 (1 February) for complete figure

\section{Quality matters-and the choice of} indicator matters too

EDITOR-Results of the analysis by Joseph add new data and a remarkable twist to existing knowledge on weaknesses in the accuracy of the data that the Institute for Scientific Information (now part of the Thomson company) uses. ${ }^{1}$ Although the institute has long struggled to avoid mistakes, the vast amount of data needed to create its products emphasises the importance of more stringent quality checks. These controls are impossible to perform by users of the institute's indices and databases, since most users do not have access to the original, raw data-access, for example, to data on which articles were counted to be part of the denominator of the bibliographical "impact factor". 2

The results offered by Joseph are a reminder that the impact factor is often not the scientometric indicator of choice. If you want to know the bibliographical "impact" of a journal then you should first consider looking at the total number of citations received by such a journal (not just those received over the previous two years). ${ }^{23}$ In passing you are likely to avoid the pitfall uncovered by Joseph: the total number of citations received is not much influenced by the "number of items" chosen to compute the bibliographical impact factor.

With increasing access via the internet to the data of the Institute of Scientific Information, more attention is being devoted to the specific number of citations received by each individual article. This will not be a magic bullet, ${ }^{3}$ but it should further contribute to avoid another intrinsic "weakness" of bibliographical impact factors, for which no one is to blame: they are just the average of a highly skewed distribution; often, $85 \%$ of citations received "by a journal" are actually received by about $15 \%$ of the articles it published. ${ }^{4}$ Much of the appeal of impact factors stems precisely from the fact that an average is so simple a measure. ${ }^{23}$ But as scientists we surely can go beyond that.

Miquel Porta head, Clinical and Molecular Epidemiology of Cancer Unit Institut Municipal d'Investigació Mèdica, Carrer de Dr Aiguader, 80, E-08003 Barcelona, Spain mporta@imim.es

Competing interests: None declared.

1 Joseph KS. Quality of impact factors of general medical journals. BMJ 2003;326:283. (1 February.)

2 Porta M. The bibliographic "impact factor" of the Institute for Scientific Information, Inc: how relevant is it really for public health journals? I Epidemiol Community Health 1996;50:606-10.

3 Porta M. Factor de impacto bibliográfico (Science Citation Index y Social Sciences Citation Index) de las principales revistas de medicina preventiva, salud pública y biomedicina. Algunas cifras, algunas impresiones. Revisiones en Salud Pública 1993:3:313-47.

Seglen PO How representative is the journal impact factor? Res Eul 1992:2:143-9.

Research quality can be assessed by using combination of approaches

EDITOR-Although Porta's suggestion [above] on the use of the number of citations received by each article is an improvement over the journal impact factor as a measure of a publication's research quality, it does not solve the problem of different practices in citing references between disciplines, which is largely unrelated to quality. ${ }^{2}$

For example, when I conducted a title search for articles in 1995 on the Institute for Scientific Information's web of science database on 10 February 2003, I found that the number of citations for the top 10 papers in the BMJ, Lancet, New England Journal of Medicine, JAMA, and Annals of Internal Medicine on malaria (an average of 64) and diarrhoea (31) are substantially lower than those for coronary heart disease (435) and breast cancer (289). As I and my co-authors have suggested, ${ }^{2}$ the citation number of individual papers should be adjusted according to discipline to improve on an imperfect but widely used indicator of research quality. However, the inherent limitations of a single numerical summary measure and the lack of empirical evidence on the effectiveness of traditional peer review indicate the need to assess research quality using a combination of approaches, including post-publication peer review, indicators of the social impact 
of research, and the evaluation of research performance by independent expert panels using transparent and evidence based criteria. $^{3-5}$

Joseph L Y Liu research fellow

Centre for Statistics in Medicine, Institute of Health Sciences, University of Oxford, Oxford OX3 7LF joseph.liu@cancer.org.uk

Competing interests: None declared.

1 Joseph KS. Quality of impact factors of general medical journals. BMJ 2003;326:283. (1 February.)

2 Tang JL, Wong TW, Liu JLY. Adjusted impact factors for comparisons between disciplines. I Epidemiol Community Health 1999;53:739-40.

3 Smith R. Unscientific practice flourishes in science. $B M J$ 1998; 317:1036-40.

4 Jefferson TO, Alderson P, Davidoff F, Wager E. Editorial peer-review for improving the quality of reports of biomedical studies. In: Cochrane Library. Issue 1. Oxford: Update Software, 2003.

5 Altman DG. Poor-quality medical research. What can journals do? JAMA 2002;287:2765-7.

\section{Overseas members of the BMA}

Forgotten members should be recognised

EDITOR-I resonated with Kisely's letter on the forgotten overseas members of the BMA. ${ }^{1}$ After years within the vineyard of the NHS my first instinct is relief not to be part of BMA politics, GMC utterances, and royal college solemnities. They can be more comfortably observed from here.

However, we are now doctors in a global village and should encourage health workers to be internationalists. There should be an internationally recognised and accredited medical qualification. The citizens of the world should reasonably expect common standards and expertise from the medical profession. In the same way, the continued validation of skills and registration must work towards an international perspective.

The BMA is a British phenomenon, but the $B M J$ is an international publication. Plainly, overseas members should be listened to, and in the age of electronic communication this is not difficult. International committees should be international. The same arguments apply to the royal colleges, which are often strikingly parochial.

In a working lifetime I have worked three times overseas and twice returned to work in Britain. This is not unique. Such medical nomads may be difficult people with their different exposures, perspectives, and experience, but they are important and could make important contribution.

Peter A Sims professor of public health medicine School of Medicine, PO Box 5623, Boroko, NCD 111, Papua New Guinea

petersims@upng.ac.pg

Competing interests: None declared.

1 Kisely S. The exiled tribe: don't forget overseas members of the BMA. BMJ 2003;326:103. (11 January.)

\section{Time for Boston tea party?}

EDITOR-Kisely wrote about the forgotten overseas members of the BMA. ${ }^{1}$ It is surprising that the BMA welcomes members who are working overseas to its ranks but in the 21 st century doesn't offer them representation even on the "overseas" committeewhich I suppose only represents doctors working in the United Kingdom who have arrived "from" overseas.

UK law has now incorporated the European Commission's human rights principles-isn't the council of the BMA therefore obliged by law to offer realistic representation? This is a challenge to the president-does he or does he not support democratic representation? I assume he does. Will he do anything? Perhaps he could be asked to reply-in both electronic and printed versions of the $B M J$ ?

\section{S G Barber consultant physician}

St Bernard's Hospital, Gibraltar

doctorbarber@hotmail.com

\section{Competing interests: None declared.}

1 Kisely S. The exiled tribe: don't forget overseas members of the BMA. BMJ 2003;326:103. (11 January.)

Member of the "tossed aside" tribe speaks

EdiTor-Kisely's letter on the BMA's overseas members was the first time in the whole debate about reaccreditation that I have seen any reference to those of us currently working outside the United Kingdom. ${ }^{1}$ The impression being given is that we are going to be tossed aside as no longer wanted by the General Medical Council. The NHS is so short of staff that it is actively recruiting doctors from overseas to fill vacant positions that cannot be filled by people trained in the United Kingdom.

I left my partnership three and half years ago to live in the United States. A recent email from one of my old colleagues asked me, not for the first time and only half jokingly, if I would like my old job back. This illustrates how difficult it is to fill general practice vacancies in the United Kingdom. The reaccreditation process will compound the problem yet again by excluding many experienced, NHS trained doctors who just happen to have been working abroad at this crucial moment in the history of the GMC. With 15 years' NHS experience, I would like very much to keep my GMC registrationwill someone please let me know what I will have to do to keep it?

Jane L McLennan research associate University of California at San Francisco Cancer Risk Program, Comprehensive Cancer Center, San Francisco, CA 94143, USA jmclennan@cc.ucsf.edu

Competing interests: None declared.

1 Kisely S. The exiled tribe: don't forget overseas members of the BMA. BMJ 2003;326:103. (11 January.)

\section{BMA responds}

EDITOR-While the BMA values its overseas members, I make no apology for the fact that its representative structure is based largely (but not entirely) around doctors who live and work in the United Kingdom. Only just over $2.5 \%$ of members pay the "overseas" subscription, which gives them the benefit of a $37.5 \%$ discount from the standard annual payment for UK residents.
Although it is true that overseas members cannot stand for election to BMA council, overseas branches can nominate representatives to the representative body, entitling them to attend the annual representative meeting. The overseas branch network has dwindled over the years and the seats allocated to them in the annual representative meeting are rarely fully occupied, presumably from simple lack of interest.

The major craft committees are exclusively drawn from members based in the United Kingdom, but those living overseas are not precluded from being appointed to other important committees such as the international committee or the medical ethics committee. At a later stage in the association-wide governance review now being undertaken, we shall be considering the adequacy of both the benefits of membership and the opportunities for participation for overseas members and branches.

Kisely also mentions revalidation. Far from ignoring overseas based doctors in our discussions with the General Medical Council, we have raised specific concerns about how they (and other doctors not in managed appraisals systems) may revalidate, and we understand that the GMC is developing a range of tools which will assist doctors working overseas who wish to provide independent evidence for revalidation. The debate about revalidation can be followed by non-resident members on the BMA and GMC websites. And for the first time this year overseas members will be mailed a copy of the annual report of BMA council.

Jeremy Strachan secretary BMA, London WC1H 9JP

\section{Four futures for scientific and medical publishing}

\section{It's a wiki wiki world}

EDitor-Abbasi et al are to be congratulated on their crystal ball gazing. ' Communication in the modern world is clearly changing, and even in the world of medical publishing the old ways are giving way to the new. Although Homer may make some minor changes, his children will never follow in his footsteps.

The future belongs to Lisa. Smart and articulate, she will thrive in a milieu that she manipulates so that useful information will flow towards her. By participating in her online communities and achieving status in these groups, she will be the one who knows (or at least who knows who knows) the required information.

Lisa will have accepted the basic precepts of the cluetrain manifesto (www. cluetrain.com), its essence being that communication in the modern world is based on continuous online conversations by email between service providers and clients, their immediacy and formality being somewhere between a letter and a telephone call. Lisa will participate continuously in her global 
conversations, irrespective of her physical location. The lines between her work and leisure will blur.

Abbasi et al seem unsure as to how many journals there will be in Lisa world. They list the range as 0 to 1 million. Conversation is great, but we still need to separate the wheat from the chaff and the signal from the noise. Fortunately the internet has given us the answer-one-the Wikipedia concept, which has developed as a result of the open source software model using free (wiki) software (www.wikipedia.org/wiki/Medicine). The essential features are a revision control system, unrestricted editing of articles on the wiki by any registered member, unrestricted membership of the wiki, and the ability to fork articles (or see current versions at the same time). In addition, no copies are deleted and the newer versions of an article comprise the original article with all additions made cumulatively.

David G Guest general practitioner

Lismore, NSW 2480, Australia

dguest@zeeclor.mine.nu

Competing interests: DG is a deputy editor of the online medical journal, Medicine Australia (www.medicineau.net.au/), which is run by the Northern Rivers Division of General Practitioners but has no other association with online or print media journals.

Abbasi K, Butterfield M, Connor J, Delamothe T, Dutton S,
Hadridge P, et al. Four futures for scientific and medical publishing. BMJ 2002;325:1472-5. (21 December.)

\section{There needs to be a fifth world}

EDITOR-For scientists and medical professionals the Lisa world scenario poses the biggest challenge, at least for the near future. ${ }^{1}$ Today, the internet is crowded with spurious, if not false, information. Until some way is found to help users in identifying what is chaff and what is substance, it will be dangerous for authors to bypass publishers who spend a lot of time, energy, and money in peer reviewing submitted articles and posting their papers on the internet. The peer review system may not be faultless, but at least it serves the scientific and medical community well in deterring some quack would-be authors.

Furthermore, online information is increasingly free to users in places such as west Africa, but access is still very expensive for most potential users because the personal computer, the phone line, and the power and subscription to internet providers are still scarce and costly. Paper is still cheaper, unlike in some other parts of the world (this might be changing but only slowly).

The Lisa world of publishing will exacerbate plagiarism unless website providers will guarantee to archive publications for long periods of time so that references can be checked for authenticity long after they are used in bibliographies. Perhaps there should be a fifth world, where publishers give authors greater rewards for their work so as to retain their confidence. This fifth world will ultimately benefit everyone, the scientist, the medical profes- sional, and the patient, wherever they may be located on the globe.

Joseph Ana managing editor

BMJ West Africa, UK Office, Luton LU2 7AE bmjwa.bmjwa@virgin.net

Competing interests: JA is managing editor of $B M J$ West Africa edition and chief executive of BMJWA's Health Information Resource Centre, Calabar, Nigeria, which stands to be affected in some way by future developments in medical publishing.

1 Abbasi K, Butterfield M, Connor J, Delamothe T, Dutton S, Hadridge P, et al. Four futures for scientific and medical publishing. BMJ 2002;325:1472-5. (21 December.)

\section{Applying evidence is problem not just for educational quality}

EDITOR-Greenhalgh et al describe the difficulties encountered when attempting to apply the techniques of evidence based medicine to complex problems in medical education. ${ }^{1}$ However, their study also illustrates that some broad principles can be generalised to help identify and synthesise evidence.

At the risk of oversimplifying, the "system" for the "systematic" review may require amendment, but the shift from selective narrative to systematic review still brings benefit. If nothing else the easy claims of success resulting from various educational innovations are made to look less certain, and educational decision makers may be reminded of the need to pay more attention to the detailed implementation of change in a specific context.

But why limit this lesson to educational developments? We have argued elsewhere that the same complexities arise in relation to many healthcare questions, particularly those relating to questions of complex service delivery. ${ }^{2}$ For us the challenge was managing the transition from child to adult services, but the problems-imprecise terminology for searching the literature, lack of good quality research, and multiple qualitative questions-were remarkably similar. ${ }^{3}$

Greenhalgh's suggested sequence for evidence based educational development could equally be applied to many healthcare developments. We suggest a change in emphasis for the latter stages of the sequence. Rigorous in-depth primary research may not always be viable, but client focused evaluation, assessing issues identified in the review of the evidence, is simple good practice (quality assurance). In this way development can be informed by the best available evidence but not necessarily stymied by the need to devote considerable resources to further research, one of the oft overlooked potential benefits of evidence based practice.

Peter Griffiths senior lecturer

peter.griffiths@kcl.ac.uk

Angus Forbes research fellow

Florence Nightingale School of Nursing and

Midwifery, King's College, London SE1 8WA
Competing interests: None declared.

1 Greenhalgh T, Toon P, Russel J, Wong G, Plumb L, MacfarGreenhalgh 1, Toon P, Russelj, Wong G, Plumb L, Macfarane F. Transferability of principles of evidence based medicine to improve educational quality: systematic review and case study of an online coursed in primary health care
BMJ 2003;326:142-5. (18 January.)

Forbes A, Griffiths P. Methodological strategies for the identification and synthesis of 'evidence' to suppor decision-making in relation to complex healthcare system

Forbes A, While A, Ullman R, Lewis S, Mathes L, Griffiths P. A mult method review to identify components of practice that may promote continuity in the transition from child to adult car for young people with chromic illness or disability. London: and Organisation Research, 2001.

\section{Seven steps to evidence based general practice}

EDITOR-In reporting the study by Prosser et al, Dobson highlights the finding that the pharmaceutical industry is the most common source of prescribing information for general practitioners. ${ }^{12}$ He misses the key point of this study: lack of time, information overload, and irrelevance of medical journals to general practice are the main barriers to general practitioners using the scientific literature. If we believe that the world of health care will be improved by directing general practitioners towards the scientific literature (a dodgy assumption) here are our seven magical steps for laying that path.

- Allow general practitioners to take on the role of healer rather than that of social worker, plumber, and travel agent

- Make general practitioners feel more valued by encouraging patients to give their doctors the same love and attention they heap on their pets

- Make consultants and academics who whinge about general practitioners' prescribing spend one day in general practice; after this experience they'll soon stop whingeing

- Rather than viewing the pharmaceutical industry as a carbuncle on the face of evidence based medicine, learn from how they communicate with general practitioners - Ask authors of papers to think more about their readers and less about their careers

- Get editors to reserve page 3 of their journals for saucy pictures

- Make scientific journals have prize draws of $£ 500000$ - to pay for this they can use the money they make from the pharmaceutical industry in advertisements and reprints.

Max Lagnado medical communications consultant Medmax Consulting Limited, Edgware HA8 9UE medmax@btconnect.com

Simone Kohll general practitioner returner Bacon Lane Surgery, Edgware HA8 5AT

Competing interests: ML left general practice because he did not have enough time to read the scientific literature. SK has just returned to general practice after a four year absence because she is bored with reading the scientific literature.

\footnotetext{
1 Dobson R. Pharmaceutical industry is main influence in GP prescribing. BMJ 2003;326:301. (8 February.)

2 Prosser H, Almond S, Walley T. Influences on GPs decision to prescribe new drugs-the importance of who says what. Fam Pract 2003;20:61-8.
} 